\title{
Controlled Natural Ventilation Coupled with Passive PCM System to Improve the Cooling Energy Performance in Office Buildings
}

\author{
Mohammad Saffari ${ }^{1,2}$, Mohit Prabhakar $^{3}$, Alvaro de Gracia ${ }^{3,4}$, Eleni Mangina ${ }^{1,5}$, Donal P. Finn ${ }^{1,2}$, \\ Luisa F. Cabeza ${ }^{3}$ \\ ${ }^{1}$ UCD Energy Institute, University College Dublin, Dublin, Ireland \\ ${ }^{2}$ School of Mechanical and Materials Engineering, University College Dublin, Dublin, Ireland \\ ${ }^{3}$ GREiA Research Group, INSPIRES Research Centre, University of Lleida, Lleida, Spain \\ ${ }^{4}$ CIRIAF Interuniversity Research Centre, University of Perugia, Peruiga, Italy \\ ${ }^{5}$ School of Computer Science, University College Dublin, Dublin, Ireland
}

\begin{abstract}
The building sector is responsible for consuming onethird of the global final energy use. In office buildings, high internal heat gains increase the cooling energy use. Thermal energy storage (TES) is a promising technology to decrease the cooling energy use, to achieve a low-carbon future, and to increase thermal comfort if properly designed. An appropriate use of the passive PCM system and natural ventilation can provide long-term energy and thermal comfort benefits. Many factors influence the efficient use of passive PCM system in buildings, such as outdoor/indoor boundary conditions, and HVAC control strategies. In office buildings, the PCM passive system integrated into the building envelope has the potential to regulate the indoor air temperature by absorbing high internal heat gains during day, however, discharging the PCM during night to work efficiently for the next day remains a challenging design criterion. The passive PCM system would not work efficiently if charging/discharging cycle is not completed. Wholebuilding energy simulation tools and numerical models are essential to deal with this issue. The present study is aimed at defining cooling energy savings in office buildings located in temperate climates applying PCM and natural ventilation passive technologies. A reference small office building was chosen and PCM panels with optimised melting temperature together with different natural ventilation control strategies were applied to an office building model. EnergyPlus airflow network capability was used to calculate the natural ventilation potential induced by wind and buoyancy effects. Simulation results have shown cooling energy savings from $8 \%$ to $15 \%$. In addition, natural ventilation could increase the efficiency of PCM by $8 \%$.
\end{abstract}

\section{Introduction}

The building sector is a key component of energy transition in the world, representing roughly $40 \%$ of total final energy consumption, where currently heat demand dedicates a major portion of this energy con- sumption to itself (IEA, 2018). The building sector accounts for almost $60 \%$ of European Union (EU) electricity consumption, and responsible for a large portion of indirect $\mathrm{CO}_{2}$ emissions. Although heat demand for air conditioning is currently dominant, but a substantial increase for cooling energy demands is expected by 2050. In both commercial and residential buildings, air conditioning systems contribute to a large amount of electricity demand to provide thermally comfortable indoor environment for occupants. Considering that the energy demand profile changes time to time and the share of variable renewable rises, electricity system flexibility needs to increase in all markets (IEA, 2017). Hence, improving the building envelope thermal performance one of the important measures for improving the energy flexibility and to decrease energy consumption of heating, ventilation and air-conditioning (HVAC) systems in buildings since $20 \%$ to $60 \%$ of all energy consumed in buildings is affected by the design and construction of the building envelope (IEA, 2013b). Cooling for indoor air conditioning in buildings could be attained by either passive or active systems or both as a hybrid cooling system. Passive cooling of buildings addresses the technologies or techniques which are used to cool the building indoor environment with no electricity usage or at least with minimum electricity usage. On the other hand, active cooling refers to technologies in which the electricity is used to run the HVAC system. Passive cooling in buildings could be achieved through evaporative cooling, earth cooling, ventilation cooling, energy storage (Waqas and Ud Din, 2013), or combinations of these technologies (Fong and Lee, 2014). In recent years, an increasing attention has been paid to enhance the flexibility of buildings through smart demand-side response strategies and latent heat storage (Lizana et al., 2018). The increased use of thermal energy storage technologies (TES) in buildings can improve demand flexibility and energy efficiency(IEA, 2013a; Mazzeo et al., 2017). These systems are promising solutions to scale down the energy consumption by taking advantage of materials with high energy storage capacity to store 
energy in terms of sensible heat and latent heat. Materials used for latent heat storage are known as phase change materials (PCM) (Cabeza et al., 2015). Due to high latent heat capacity, PCMs are able to store a high amount of energy in small temperature intervals resulting in a significant increase in the thermal mass of the building envelopes (Pielichowska and Pielichowski, 2014).

Many researchers have mentioned the advantages of PCMs in terms of cooling and heating energy savings, peak load shifting and thermal comfort improvement when applied to buildings (Kuznik et al., 2011; Soares et al., 2013; Memon, 2014). However, until today, little advancement has been achieved to improve the charging and discharging cycle of PCM-enhanced building envelopes by dissipating the stored heat in these materials (de Gracia, 2019) which is a highly important step to exploit the full potential of PCMs, otherwise, their high latent heat capacity does not function properly. Integrating two passive technologies of PCM and natural night ventilation can increase the efficiency of PCM technology if properly designed. In this method, the cool outdoor temperature at nighttime and/or early morning is used to dissipate the accumulated heat in the PCM and charge it with cool outdoor air again. Natural ventilation is an important strategy to provide free cooling in buildings and improving the indoor air quality and thermal comfort. Many important factors should be considered when designing natural ventilation system, specifically, when it is coupled with an innovative technology such as PCM. These design factors are building location, shape, and type (residential or commercial), urban pattern of the neighbouring buildings, wind velocity, wind direction, opening types, and smart control strategies. Coupling thermal mass and natural ventilation is a well-known topic (Zhou et al., 2008, 2009; Wang et al., 2009; Gagliano et al., 2014), however, further research is necessary to study the effect of hybrid cooling system using PCM with natural ventilation, and HVAC system (Evola et al., 2013; Jamil et al., 2016), together with control techniques. However, in recent years there have been progresses in the development of combined PCMventilation air conditioning system for office buildings (Monodraught, 2019), or decentralised PCM ventilation systems (Pomianowski et al., 2013). Additionally, in the existing literature the methodologies used to calculate the natural ventilation effect on the efficiency of PCM are limited to simplified and scheduled air flow rates (Solgi et al., 2019) and there is a lack of more sophisticated numerical (Saffari et al., 2017) and experimental (Barzin et al., 2015) studies for design, implementation, and analysis of such systems. The objective of the present study is to improve the energy flexibility of commercial buildings combining optimised PCM and natural ventilation as two integrated passive technologies together with natural ven- tilation and HVAC operation control strategies. The main contribution of the present paper is to numerically calculate natural ventilation airflow rates due to wind and buoyancy effects under different climatic regions using whole-building energy simulation software. The novelty of the paper is that the natural ventilation capacity is numerically calculated according to the outdoor and indoor boundary conditions when PCM is integrated into the building envelopes. The methodology used in this study could be used for automation and smart control of both commercial and residential buildings.

\section{Methodology}

\section{Reference building prototype}

A small office building prototype was selected from ASHRAE Standard 90.1- 2013 prototype building models and slightly modified (Goel et al., 2014). The small office building model is a one-story building with $511 \mathrm{~m}^{2}(27.67 \mathrm{~m} \times 18.44 \mathrm{~m})$ of conditioned floor area, as shown in Figure 1. The building has four perimeter zones, and one core zone with perimeter zone depth of $5 \mathrm{~m}$ (see Figure 2). Window-to-wall ratio is approximately $24.4 \%$ for South and $19.8 \%$ for the other tree orientations. In addition, the building has unconditioned attic space. The construction of the exterior walls and roof are wood-frame walls, and attic roof with wood joist, respectively. The foundation type is slab-on-grade. The thermal transmittance values (U-value) of external walls, ceiling, floor, and external windows are $0.5 \mathrm{~W} / m^{2}-K, 2.9$ $\mathrm{W} / m^{2}-K, 2.1 \mathrm{~W} / m^{2}-K$, and $3.5 \mathrm{~W} / m^{2}-K$.

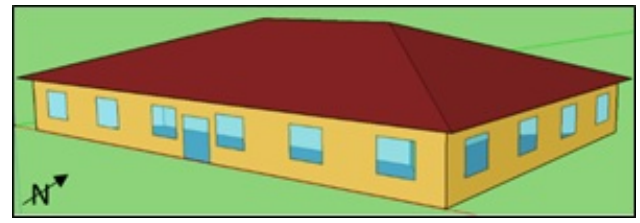

Figure 1: Reference small office building prototype.

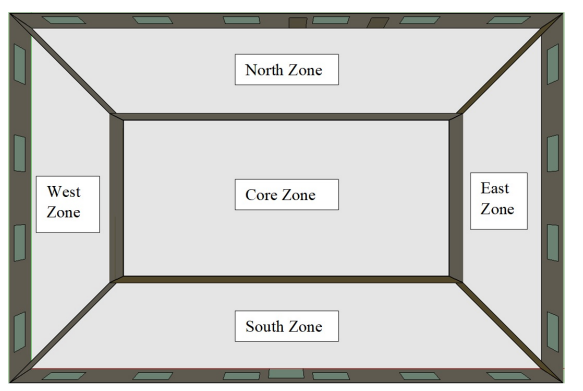

Figure 2: Perimeters of the office building.

The ASHRAE Standard 90.1 prototype building models were developed by the Pacific Northwest National Laboratory in support of the U.S. Department of Energy (DOE) Building Energy Codes Program. These building prototypes are simulated in different climate zones and could be mapped to other climate regions for international use (Thornton et al., 2011). Although it could be challenging to consider a single building prototype with its unique properties as a ref- 
erence for all existing office buildings worldwide, however, the ASHRAE Standard 90.1 prototype building models represent standard building energy models for the most common commercial buildings to be used in initial design stages, energy efficiency analysis, research and represent realistic building characteristics and construction practices (Tianzhen et al., 2015; Luddeni et al., 2018).

The building HVAC system consists of an electric airsource heat pump units per occupied thermal zone with constant air volume air distribution system. The single-speed direct expansion cooling coil gross rated cooling coefficient of performance (COP) is 4.11 and is auto-sized for a design day. The thermostat cooling setpoint control is scheduled and varies by hour. Figure 3 shows the thermostat operation schedule and the occupancy fraction for Weekdays. As the aim of study is to improve the cooling energy performance of the building in the summer season, the thermostat regulation is set to single cooling, and heating is not allowed. Since the main office zones (except core zone) are identical in terms of HVAV system, thermostat control, and internal heat gains, and on the other hand, because the air exchange between zones is not considered for simulation, only the south and east zones of the building prototype are selected for simulation to reduce the computational cost. This does not influence the methodology used in this study. Additionally, the control algorithm does not allow the heat pump to operate in tandem with the natural ventilation and when the windows are open.

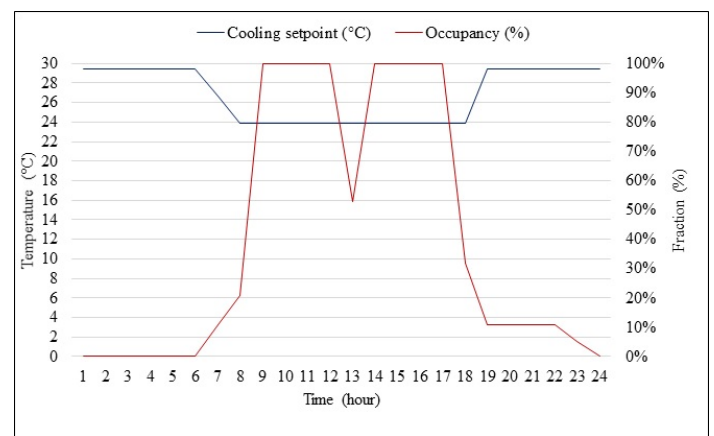

Figure 3: Thermostat cooling regulation, and occupancy schedule.

\section{Natural ventilation}

In this paper, natural ventilation was calculated using EnergyPlus simulation coupled with an airflow network model (AFN). The AFN model is a sophisticated algorithm which offers more advanced ventilation calculations as opposed to the simplified calculations offered by design flow rate and ventilation by wind and stack with open area models. AFN model is able to simulate wind- and buoyancy-driven as well as forced air distribution system multizone airflows and pressures (U.S. DOE, 2016; EnergyPlus, 2019). EnergyPlus AFN model was validated against measured data and good agreement between the simulation results and the measured data were found (Gu, 2007).
In the present study, single-sided natural ventilation driven by a combination of wind pressure and temperature difference is provided by large openings (vertical windows) (see Figure 4), and are defined as "Detailed Opening" objects with a constant discharge coefficient of 0.65 (Schulze and Eicker, 2013). This allows flow movement simultaneously in two different directions depending on stack effect and wind conditions. It should be mentioned that the air exchange between different zones was not considered and the natural ventilation was calculated at a single-zone level. The main difference of this method compared to previous studies on PCM and natural ventilation is that the amount of air going through the window opening in single-sided ventilation will depend on the wind characteristics around the building, indoor and outdoor temperatures, and the pressure variations caused by for example wind gusts, and on the size, type and location of the opening (Allocca et al., 2003).

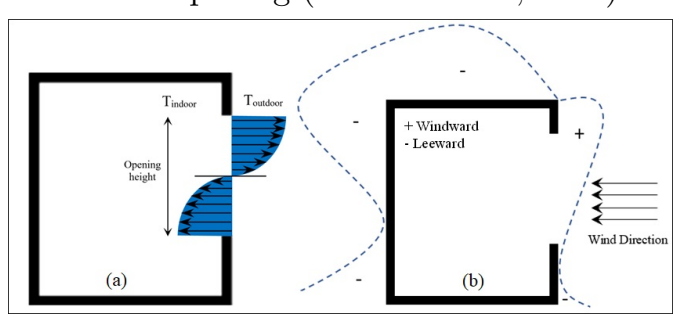

Figure 4: Indoor and outdoor pressure distribution for buoyancy-driven flow (a), wind driven flow (b).

In order to dynamically analyse the potential of the passive PCM system coupled with natural ventilation, the whole system including controls had to be simulated, because the ventilation is affected by both external and internal boundary conditions. For wind pressure coefficients (WPC), data provided by Air Infiltration and Ventilation Centre (AIVC) was used (Liddament, 1996). For the building prototype used in the present study the most suitable WPCs can be obtained for a low-rise building with length to width ratio of $2: 1$, and fully exposed shielding condition. The data for low-rise buildings is based on the compilation of wind-tunnel data published in the AIVC workshop (AIVC, 1984), and seven other bibliographical references, e.g. (Bowen, 1976) and (Wiren, 1985). The external node of $1.66 \mathrm{~m}$ (ground to midpoint elevation of windows) was selected as the reference height for local wind pressure calculation.

\section{Energy simulation scenarios}

Different scenarios have been considered to investigate the impact of different passive technologies and control strategies and their trade off on the cooling energy performance of the office building prototype and benchmark them against the reference model. With this regard, six different scenarios have been considered; Scenario (a) is the reference building (REF) which is described earlier in reference building prototype section. Scenario (b) uses the same building prototype as reference model but with macroencapsulated PCM panels (PCM-NoVent) with op- 
timised melting temperature installed on the interior surfaces of vertical external walls, internal partition walls, and ceiling. It should be noted that, in this scenario the PCM technology is the only strategy used for passive cooling without any natural ventilation system. Further information about the PCM technology and optimisation is presented in the following section. Scenario (c) uses the reference building in terms of natural nighttime ventilation (NNV) using single-sided operable windows controlled by a constant venting availability schedule which allows venting by opening $50 \%$ of all operable windows located on the south and east-faced faades of the building, independent of indoor and outdoor conditions from 12:00 am to 6:00 am for pre-cooling of the building envelopes. It should be added that when the night ventilation is active, the HVAC system is not allowed to operate. Scenario (d) is the reference building in terms of controlled natural ventilation (CNV) with hourly indoor/outdoor temperature control for operable windows. Scenario (e) is the building prototype with PCM coupled with nighttime ventilation (PCM-NNV), and finally Scenario (f) is the building prototype enhanced by PCM and natural ventilation implemented by operable windows controlled by indoor/outdoor temperature difference (PCM-CNV). In this scenario, the control system allows windows to be opened by maximum opening factor of $50 \%$ whenever the zone temperature is $3^{\circ} \mathrm{C}$ higher than outdoor dry bulb temperature, and higher than the thermostat setpoint temperature, otherwise, the operable windows will be kept closed. Table 1 summarises different simulation and control scenarios.

Table 1: A summary of energy simulation scenarios.

\begin{tabular}{|l|l|}
\hline Scenarios & Descriptions \\
\hline (a) & Reference Building (REF) \\
\hline (b) & $\begin{array}{l}\text { PCM-No Ventilation (PCM- } \\
\text { NoVent) }\end{array}$ \\
\hline (c) & Natural Night Ventilation (NNV) \\
\hline (d) & $\begin{array}{l}\text { Temperature-Controlled Natural } \\
\text { Ventilation (CNV) }\end{array}$ \\
\hline (e) & $\begin{array}{l}\text { PCM-Natural Night Ventilation } \\
\text { (PCM-NNV) }\end{array}$ \\
\hline (f) & $\begin{array}{l}\text { PCM-Temperature-Controlled Nat- } \\
\text { ural Ventilation (PCM-CNV) }\end{array}$ \\
\hline
\end{tabular}

\section{PCM characterisation}

In the present study, a macro-encapsulated panel of Rubitherm (Rubitherm, 2019) with thickness of 15 $\mathrm{mm}$ was considered. Each panel weighting $1 \mathrm{~kg}$ is filled with RT PCM with heat storage capacity equivalent to $42 \mathrm{Wh} / \mathrm{kg}$. The selected macro-encapsulated PCM has high latent heat capacity in narrow temperature ranges, and the PCM can be filled in with different temperatures depending on the application and climatic zone. To optimise the PCM melting temperature for the selected cities, the methodology which was proposed by Saffari et al. (2017) was used. In this method, the PCM h-T curve is iteratively selected which results in reduced simulation/optimisation time to find out the best PCM melting point for the selected building model. On this basis, PCM peak melting point of $25^{\circ} \mathrm{C}$ was used for Midland, Madrid, Tehran, and $23^{\circ} \mathrm{C}$ for Abu Dhabi. Table 2 shows physical properties of the selected PCM.

Table 2: Physical properties of RT24 PCM.

\begin{tabular}{|l|l|}
\hline Physical property & Value \\
\hline Specific heat & $2 \mathrm{~kJ} / \mathrm{kg} . \mathrm{K}$ \\
\hline Thermal conductivity & $0.20 \mathrm{~W} / \mathrm{m} . \mathrm{K}$ \\
\hline Melting area & $21-25^{\circ} \mathrm{C}$ \\
\hline Heat storage capacity & $160 \mathrm{~kJ} / \mathrm{kg}$ \\
\hline Max. operation temperature & $55^{\circ} \mathrm{C}$ \\
\hline
\end{tabular}

\section{Building simulation and optimisation}

EnergyPlus v8.9 (U.S. DOE, 2019) was used to carry out the simulations. EnergyPlus whole-building energy simulation software is a powerful building energy and comfort simulation tool for modelling the heat transfer in the building envelope, the energy requirements of the building, and human thermal comfort. Many studies validated EnergyPlus algorithms. For instance, the PCM algorithms were verified and validated against analytical verification (Stefan Problem), comparative testing (against Heating 7.3) and empirical validation (DuPont Hotbox) by Tabaresvelasco et al. (2012). Additionally, in many researches, simulation results obtained by PCM model of EnergyPlus were validated against experimental data (Auzeby et al., 2016). In the current study, in all models the simulation time step was set to 1 minute. All simulations were run for cooling months only (June, July, August, and September). For optimisation of the melting temperature of PCM in scenarios with PCM panels, GenOpt v3.1.1 (generic optimisation program) was utilised (Wetter, 2001). GenOpt performs optimisation of a user-defined cost function such as, annual energy consumption, thermal comfort, etc. using various numerical optimisation algorithms which could be selected by user.

\section{Climate conditions and locations}

As the main purpose of this study is to evaluate the cooling energy performance, climates with high cooling degree days were selected. Figure 5 shows the annual hourly average of wind speed, outdoor air temperature, and global horizontal solar radiation of the selected cities. The updated Köppen-Geiger Kottek et al. (2006) main climates classification was used as a reference to the selected climates. In this classification there are five letters to classify the world into five major climate regions according to the average annual precipitation, average monthly precipitation, and average monthly temperature which are A: equatorial, B: arid, C: warm temperate, D: snow, and E: polar. Moreover, the level of precipitation is defined as W: desert, S: steppe, f: fully humid, s: summer 
dry, w: winter dry, and m: monsoonal. More details are provided regarding temperature as h: hot arid, k: cold arid, a: hot summer, b: warm summer, c: cool summer, d: extremely continental, and F: polar frost.

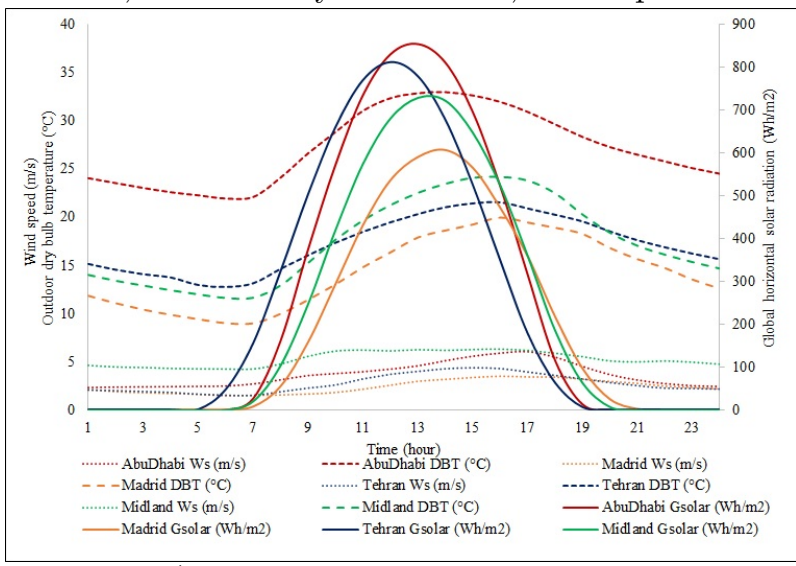

Figure 5: Annual hourly average temperature, wind, and solar radiation data of selected cities; $W_{s}$, wind speed; DBT, dry bulb temperature; $G_{s}$ olar, global horizontal solar radiation.

The updated Köppen-Geiger (Kottek et al., 2006) main climates classification was used as a reference to the selected climates. In this classification there are five letters to classify the world into five major climate regions according to the average annual precipitation, average monthly precipitation, and average monthly temperature which are A: equatorial, B: arid, C: warm temperate, D: snow, and E: polar. Moreover, the level of precipitation is defined as $\mathrm{W}$ : desert, S: steppe, f: fully humid, s: summer dry, w: winter dry, and m: monsoonal. More details are provided regarding temperature as h: hot arid, k: cold arid, a: hot summer, b: warm summer, c: cool summer, d: extremely continental, and F: polar frost. Further information about the selected climates including elevation from sea level, and cooling degree days (CDD) can be seen in Table 3 .

Table 3: Data of the selected climates.

\begin{tabular}{|l|l|l|}
\hline Weather/Location & Elevation & CDD \\
\hline BSk-Midland (USA) & $872 \mathrm{~m}$ & 3043 \\
\hline BWh-Abu Dhabi (UAE) & $27 \mathrm{~m}$ & 6254 \\
\hline Cfa-Madrid (Spain) & $582 \mathrm{~m}$ & 2057 \\
\hline Csa-Tehran (Iran) & $1190 \mathrm{~m}$ & 3230 \\
\hline
\end{tabular}

\section{Results}

In this section, the effect of different natural ventilation strategies on the energy performance of the office building with and without passive PCM system in different climates is investigated. Different scenarios were considered to find out the best combination of PCM and natural ventilation to enhance the overall cooling energy performance of the office building. Figure 6 shows the simulation results obtained from different passive technologies and natural ventilation control strategies used in this study.

All energy saving results obtained by comparing en-

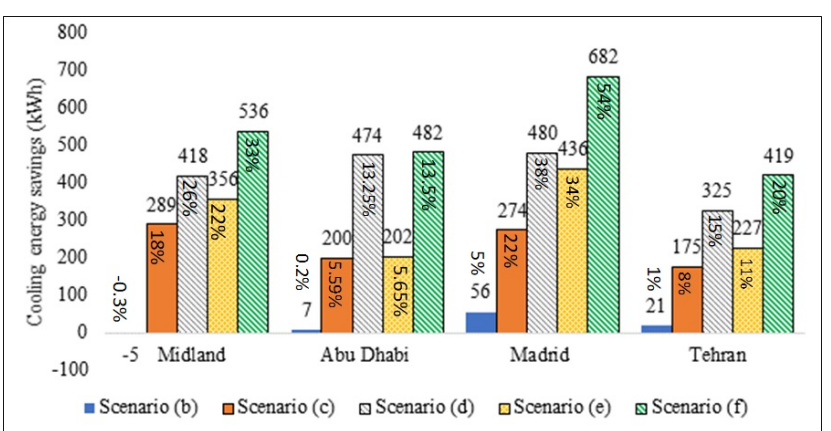

Figure 6: Cooling energy savings for each scenario.

ergy consumption of the reference building or Scenario (a) which are $1639 \mathrm{kWh}, 3575 \mathrm{kWh}, 1263 \mathrm{kWh}$, and $2127 \mathrm{kWh}$ for Midland, Abu Dhabi, Madrid, and Tehran, respectively. Results show that natural ventilation has a significant potential in cooling energy savings of the office buildings (small office building prototype). Also, it can be observed from the Figure 6 that the natural ventilation has better benefits when controlled through temperature difference between outdoor and indoor compared to ventilation during night. This could be seen by looking at results of Scenarios (c) and (d) where the passive cooling system was based only on natural cooling through ventilation. Natural ventilation strategies achieved substantial cooling energy savings in all studied climates. The higher cooling energy savings was $38 \%$ (480 kWh) for Madrid and 13\% (474 kWh) for Abu Dhabi. The reason for lower energy savings in $\mathrm{Abu}$ Dhabi is the elevated outdoor temperature especially during nighttime so the heat stored in the building envelope during day cannot be adequately discharged to the outdoor environment during night and get ready to store heat for the next hours or day. This issue is of a very high importance in case of PCMenhanced envelopes. However, these results might vary depending on the building type, building size, internal gains, control strategies, and location and might not be suitable for all commercial buildings. Hence, simulation and optimisation analysis are essential steps for initial design and assessment of such technologies. From these results it could be concluded that by applying only control systems and operable openings in office building considerable cooling energy savings could be obtained. In addition, it should be highlighted that using only PCM passive technology does not achieve considerable cooling savings in office buildings with high internal heat gains. This happens since PCM cannot be solidified during night to be functional again next day and remains in its liquid phase. By looking at the results of Scenario (b) in different cities this issue can be clearly observed. For instance, in Madrid the savings were only 5\% (56 $\mathrm{kW})$ and in Midland $-0.3 \%(-5 \mathrm{kWh})$. However, and more importantly, it can be noticed that the cooling energy performance is further enhanced if the natural ventilation is coupled with passive PCM system, except for Abu Dhabi, where coupling natural ven- 
tilation with passive PCM system has negligible impact due to the fact explained earlier. The highest cooling energy savings were achieved in Scenario (f) where natural ventilation controlled through temperature difference and was coupled with passive PCM system. The corresponding energy savings in Madrid, Midland, Tehran and Abu Dhabi were recorded as $54 \%$ (682 kWh), 33\% (536 kWh), 20\% (419 kWh), and $13 \%$ (482 $\mathrm{kWh}$ ), respectively. Based on these findings, it can be concluded that cold outside air removes the heat gains during the day from the passive PCM system and charge it for the next cycle. The consequent cooled system reduces the peak cooling load, thereby decreasing the cooling energy demand. As an example, in case of Scenario (f) a detailed analysis has been provided in Figure 7 for two days simulation under the climatic condition of Madrid (1st to 2nd of July).

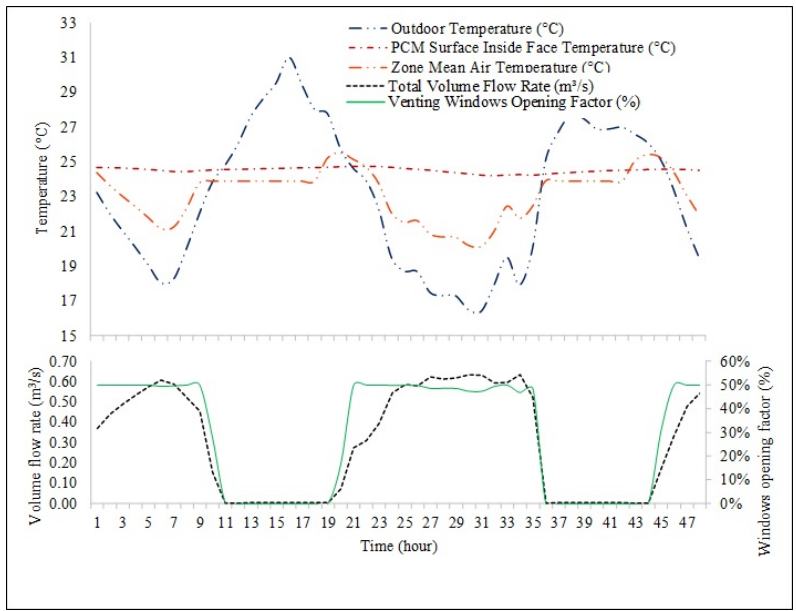

Figure 7: Indoor/outdoor temperature, calculated air volume flow rate due to natural ventilation, and operable window operation.

Figure 7 demonstrates outdoor dry bulb temperature, indoor mean air temperature, PCM inside face surface temperature of the south wall of the south zone, opening factor of all operable windows on the south wall, and numerically calculated air volume flow rate due to natural wind and buoyancy forces. It can be observed that when outdoor air temperature was less than zone air temperature during night, early morning, and evening, the control system opens the venting windows to provide natural cooling and charge the PCM incorporated into the building envelopes with the cool outdoor air. Also, it can be seen that during nighttime the natural ventilation provides 0.4 to above $0.6 \mathrm{~m}^{3} / \mathrm{s}$ of air flow rate (all six large openings in the south wall). By looking at the same figure it can be derived that the 2nd of July, at 7 am the PCM surface temperature is around $24^{\circ} \mathrm{C}$ which is below the melting point of the PCM used for Madrid $\left(25^{\circ} \mathrm{C}\right)$. This shows that the natural ventilation and the applied controlled strategy could charge the PCM passive system with cool night and morning outdoor temperature and increase the efficiency of the PCM passive system.

\section{Conclusions}

This present paper evaluates the effect of natural ventilation and PCM on the energy performance of office buildings in different climates with high cooling degree days. For this purpose, low temperature outside air is used to remove the heat gains in the office building with passive PCM system. To enhance the benefit of natural ventilation or free cooling different scenarios and natural ventilation control strategies were implemented. This study aims to address the limitation of passive PCM cooling system in which the accumulated heat in the PCM is discharged to the indoors, thus resulting in no substantial energy savings or higher energy consumption for space cooling .The results presented in the study demonstrates that better control of natural ventilation provides significant benefits in term of energy savings in office buildings. But, the influence of free cooling is maximised in the case of PCM enhanced office buildings with proper natural ventilation and control systems. Office buildings located in climates with low nocturnal temperatures such as Madrid with PCM and natural ventilation controlled by indoor/outdoor temperature difference (Scenario (f)) can achieve up to $54 \%$ higher cooling energy savings compared to office buildings without passive PCM and natural ventilation passive system. In addition, using only PCM as a passive cooling system in office buildings with high internal heat gains leads to negligible energy savings. The methodology used in the present study can be extended to more climates and different types of buildings, and further control and optimisation strategies could be applied for optimising the passive cooling systems based on PCM and natural ventilation.

\section{Acknowledgements}

This publication has emanated from research supported (in part) by Science Foundation Ireland (SFI) under the SFI Strategic Partnership Programme Grant Number SFI/15/SPP/E3125. The opinions, findings and conclusions or recommendations expressed in this material are those of the authors and do not necessarily reflect the views of the SFI. Furthermore, this publication has received funding from the European Unions Horizon 2020 research and innovation programme under the Marie Sklodowska-Curie grant No. 712949 (TECNIOspring PLUS) and from the Agency for Business Competitiveness of the Government of Catalonia. GREiA is a certified agent TECNIO in the category of technology developers from the Government of Catalonia. This work was partially funded by the Ministerio de Economa $y$ Competitividad de España (ENE2015-64117-C5-1-R (MINECO/FEDER)). The authors from the University of Lleida would like to thank the Catalan Government for the quality accreditation given to their research group (2017 SGR 1537). 


\section{References}

AIVC (1984). AIVC Technical Note 13.1 Wind Pressure Workshop. In Wind Pressure Workshop Proceedings, pp. 204. AIVC. Wind Pressure Workshop Proceedings AIC-TN-13.1-84, Brussels (Belgium), 21-22 March 1984.

Allocca, C., Q. Chen, and L. R. Glicksman (2003, sep). Design analysis of single-sided natural ventilation. Energy and Buildings 35(8), 785-795.

Auzeby, M., S. Wei, C. Underwood, J. Tindall, C. Chen, H. Ling, and R. Buswell (2016, aug). Effectiveness of Using Phase Change Materials on Reducing Summer Overheating Issues in UK Residential Buildings with Identification of Influential Factors. Energies 9(8), 605.

Barzin, R., J. J. Chen, B. R. Young, and M. M. Farid (2015, nov). Application of PCM energy storage in combination with night ventilation for space cooling. Applied Energy 158, 412-421.

National Aeronautical Establishment, National Research Council Canada, Canada, report LTR-LA209 (1976). A wind tunnel investigation using simple building models to obtain mean surface wind pressure coefficients for air infiltration estimates.

Cabeza, L., I. Martorell, L. Miró, A. Fernández, and C. Barreneche (2015). Introduction to thermal energy storage (TES) systems. In L. F. Cabeza (Ed), Advances in Thermal Energy Storage Systems, Chapter 1, pp. 1-28. United Kingdom: Elsevier.

de Gracia, A. (2019, feb). Dynamic building envelope with PCM for cooling purposes Proof of concept. Applied Energy 235, 1245-1253.

EnergyPlus (2019). EnergyPlus v8.7 Input Output Reference: The Encyclopedic Reference to EnergyPlus Input and Output. https://energyplus. net/sites/all/modules/custom/nrel_custom/ pdfs/pdfs_v8.9.0/InputOutputReference.pdf. Online; accessed 2019-01-30.

Evola, G., L. Marletta, and F. Sicurella (2013, jan). A methodology for investigating the effectiveness of PCM wallboards for summer thermal comfort in buildings. Building and Environment 59, 517-527.

Fong, K. and C. Lee (2014, jun). Investigation on hybrid system design of renewable cooling for office building in hot and humid climate. Energy and Buildings 75, 1-9.

Gagliano, a., F. Patania, F. Nocera, and C. Signorello $(2014$, apr). Assessment of the dynamic thermal performance of massive buildings. Energy and Buildings 72, 361-370.
U.S. Department of Energy (2014). Enhancements to ASHRAE Standard 90.1 Prototype Building Models.

Gu, L. (2007). Airflow network modeling in EnergyPlus. In Building Simulation 2007, pp. 964-971. 10th International Building Performance Simulation Association Conference and Exhibition, Beijing (China), 3-6 September 2007.

International Energy Agency (2013a). Technology Road Map - Energy-efficient Buildings: Heating and Cooling Equipment.

International Energy Agency (2013b). Technology Road Map:Energy efficient building envelopes.

International Energy Agency (2017). Energy Technology Perspectives 2017.

International Energy Agency (2018). World Energy Outlook 2018.

Jamil, H., M. Alam, J. Sanjayan, and J. Wilson (2016). Investigation of PCM as retrofitting option to enhance occupant thermal comfort in a modern residential building. Energy and Buildings 133, 217-229.

Kottek, M., J. Grieser, C. Beck, B. Rudolf, and F. Rubel (2006). World map of the KöppenGeiger climate classification updated. Meteorologische Zeitschrift 15(3), 259-263.

Kuznik, F., D. David, K. Johannes, and J.-J. Roux (2011, jan). A review on phase change materials integrated in building walls. Renewable and Sustainable Energy Reviews 15(1), 379-391.

Liddament, M. W. (1996). A guide to energy efficient ventilation. Air Infiltration and Ventilation Centre. Coventry (UK).

Lizana, J., D. Friedrich, R. Renaldi, and R. Chacartegui (2018, nov). Energy flexible building through smart demand-side management and latent heat storage. Applied Energy 230, 471-485.

Luddeni, G., M. Krarti, G. Pernigotto, and A. Gasparella (2018, aug). An analysis methodology for large-scale deep energy retrofits of existing building stocks: Case study of the Italian office building. Sustainable Cities and Society 41, 296-311.

Mazzeo, D., G. Oliveti, and N. Arcuri (2017). Definition of a new set of parameters for the dynamic thermal characterization of PCM layers in the presence of one or more liquid-solid interfaces. Energy and Buildings 141, 379-396. 
Memon, S. A. (2014). Phase change materials integrated in building walls: A state of the art review. Renewable and Sustainable Energy Reviews 31, 870-906.

Monodraught (2019). Monodraught Natural Ventilation. https://www.monodraught.com/products/ hybrid-ventilation. Online; accessed 2019-0130 .

Pielichowska, K. and K. Pielichowski (2014, aug). Phase change materials for thermal energy storage. Progress in Materials Science 65, 67-123.

Pomianowski, M., P. Heiselberg, and Y. Zhang (2013, dec). Review of thermal energy storage technologies based on PCM application in buildings. Energy and Buildings 67, 56-69.

Rubitherm (2019). Rubitherm Technologies GmbHCSM modules. http://www.rubitherm.de/ english/pages/02h_air_heating_systems.htm. Online; accessed 2019-01-30.

Saffari, M., A. de Gracia, C. Fernández, and L. F. Cabeza (2017, sep). Simulation-based optimization of PCM melting temperature to improve the energy performance in buildings. Applied Energy 202, 420-434.

Saffari, M., A. de Gracia, S. Ushak, and L. F. Cabeza (2017, dec). Passive cooling of buildings with phase change materials using whole-building energy simulation tools: A review. Renewable and Sustainable Energy Reviews 80, 1239-1255.

Schulze, T. and U. Eicker (2013, jan). Controlled natural ventilation for energy efficient buildings. Energy and Buildings 56, 221-232.

Soares, N., J. Costa, a.R. Gaspar, and P. Santos (2013, apr). Review of passive PCM latent heat thermal energy storage systems towards buildings' energy efficiency. Energy and Buildings 59, 82-103.

Solgi, E., Z. Hamedani, R. Fernando, B. Mohammad Kari, and H. Skates (2019, jan). A parametric study of phase change material behaviour when used with night ventilation in different climatic zones. Building and Environment 147, 327336.

National Renewable Energy Laboratory, Denver, Colorado, U.S. (2012). Verification and Validation of EnergyPlus Conduction Finite Difference and Phase Change Material Models for Opaque Wall Assemblies.

U.S. Department of Energy (2011). Achieving the 30\% Goal: Energy and Cost Savings Analysis of ASHRAE Standard 90.1-2010.
Tianzhen, H., M. A. Piette, Y. Chen, S. H. Lee, S. C. Taylor-Lange, R. Zhang, K. Sun, and P. Price (2015). Commercial Building Energy Saver: An energy retrofit analysis toolkit. Applied Energy 159, 298-309.

U.S. Department of Energy (2016). EnergyPlus Engineering Reference: The Reference to EnergyPlus Calculations.

U.S. DOE (2019). EnergyPlus Dynamic Building Simulation. https://energyplus.net/. Online; accessed 2019-01-30.

Wang, Z., L. Yi, and F. Gao (2009, oct). Night ventilation control strategies in office buildings. Solar Energy 83(10), 1902-1913.

Waqas, A. and Z. Ud Din (2013, feb). Phase change material (PCM) storage for free cooling of buildingsA review. Renewable and Sustainable Energy Reviews 18, 607-625.

Wetter, M. (2001). GenOpt - A Generic Optimization Program. In Proceedings of Seventh International IBPSA Conference, pp. 601-608. IBPSA. Rio de Janeiro (Brazil), 13-15 August 2001.

National Swedish Institute for Building Research, Gavle, Sweden (1985). Effects of surrounding buildings on wind pressure distributions and ventilation losses for single family housesM85: 19 ..

Zhou, G., Y. Yang, X. Wang, and S. Zhou (2009, jan). Numerical analysis of effect of shape-stabilized phase change material plates in a building combined with night ventilation. Applied Energy $86(1)$, $52-59$.

Zhou, J., G. Zhang, Y. Lin, and Y. Li (2008, jan). Coupling of thermal mass and natural ventilation in buildings. Energy and Buildings 40(6), 979-986. 